\title{
Recorregut de recerca geològica i geoambiental per la comarca de l'Anoia: des de la Panadella a Santa Maria del Camí i a Jorba
}

Josep Maria Mata-Perelló

Joaquim Sanz Balagué

\section{XARAGALL \\ REVISTA DE CIÈNCIES DE LA CATALUNYA CENTRAL} n. 11

NOVEMBRE 2014 


\section{RECORREGUT DE RECERCA GEOLÒGICA I GEOAMBIENTAL PER LA COMARCA D'ANOIA: DES DE LA PANADELLA A SANTA MARIA DEL CAMÍ I A JORBA}

\section{Josep Maria Mata-Perelló}

Museu de geologia Valentí Masachs, Escola Politècnica Superior d'Enginyeria de Manresa (EPSEM), Universitat Politècnica de Catalunya · BarcelonaTech (UPC), 08272 Manresa, Spain

\section{Joaquim Sanz Balagué}

Departament d'Enginyeria Minera i Recursos Naturals (EMRN), Escola Politècnica Superior d'Enginyeria de Manresa (EPSEM), Universitat Politècnica de Catalunya - BarcelonaTech (UPC), 08272 Manresa, Spain

Paraules clau: Depressió Geològica de l'Ebre, materials terciaris, materials quaternaris, Patrimoni miner

\section{Resum}

Itinerari realitzat el 12 de gener de 2014. En aquesta ocasió, es realitzarà un recorregut geològic a través de diferents indrets de la Depressió Geològica de L'Ebre; i més concretament pels sectors corresponents a la seva Depressió Central. Així, tot el recorregut transitarà entre afloraments dels materials terciaris (de l'Eocè i de l'Oligocè) i quaternaris que reblen aquesta depressió.

Així, inicialment es transitarà al llarg de tot aquest recorregut, per la comarca de l'Anoia (Catalunya Central), iniciant el recorregut a la Panadella, a la Segarra Anoienca, per a finalitzarlo al poble de Jorba. 


\section{Objectius fonamentals}

Els objectius fonamentals que es pretenen aconseguir en aquest itinerari, es poden concretar en els següents aspectes generals:

1. Observació i descripció dels materials terciaris (exclusivament del Paleogen, i més concretament de l'Eocè i de I'Oligocè) de la Depressió Geològica de l'Ebre (i més exactament de la seva Depressió Central). Així, el recorregut de l'itinerari discorrerà entre els afloraments del Complex Lacustre d'Anoia (amb la Formació Artés, del trànsit de l'Eocè a l'Oligocè) i els del Complex Lacustre de la Segarra (amb les calcàries de la Panadella, ja de l'Oligocè). Tots aquests terrenys constitueixen el subsòl dels diferents sectors, per entre els quals discorre el present itinerari. De fet, el recorregut l'iniciarem dintre del Complex Lacustre de la Segarra, per a finalitzar-lo dintre del Complex Lacustre d'Anoia, baixant topogràficament i en la sèrie estratigràfica.

2. Observació de les estructures locals de la Depressió Geològica de l'Ebre, al llarg del recorregut de l'itinerari; tot i això, no cal oblidar que el recorregut transitarà per una de les zones més estables de la depressió, alterada solament per alguns plecs relacionats amb els nivells de guixos.

3. Observació i reconeixement de les mineralitzacions evaporítiques guixoses situades pels voltants de Jorba. Aquests materials, en aquest indret, es relacionen amb els guixos de Clariana, situats dintre de la Formació Artés..

4. Observació de les explotacions relacionades amb els materials anteriors, com les següents, d'acord amb el sentit de la marxa de l'itinerari:

4C) de les explotacions dels materials carbonatats de la Panadella-Carbassí, (dintre de la comarca d'Anoia), relacionades sobre els nivells de les calcàries de la Panadella de la Formació Tàrrega.

4B) de les explotacions dels materials carbonatats de la Montmaneu, (dintre de la comarca d'Anoia), relacionades sobre els nivells de les calcàries d'Albarells de la Formació Tàrrega.

4C) de les ja esmentades explotacions guixoses de Jorba, situades entre els materials de la Formació Artés; en concret del guixos de Clariana.

5. En tots els casos, a les explotacions anteriors, s'observaran les restauracions efectuades en elles.

6. S'observaran, al llarg de tot el recorregut, els diferents elements relacionats amb el Patrimoni Geològic i Miner. 


\section{Antecedents}

Pel que fa al recorregut del present itinerari, existeixen diversos antecedents bibliogràfics parcials. Entre els antecedents parcials, farem esment dels següents treballs nostres: MataPerelló (1996, 1997, 1999, 2000 i 2001, 2005 i 2012).

Pel que fa a la descripció de les mineralitzacions, seguirem fent esment d'alguns altres treballs nostres: Mata-Perelló (1990 i 1991); el primer relatiu a la comarca de l'Anoia, el segon al conjunt de les mineralitzacions catalanes.

I, finalment, pel que fa a l'estructura geològica de la zona per la qual discorre l'itinerari, farem esment dels treballs de: Guimerà et altri (1982) i de RIBA et altri (1976).

Tots aquests treballs referenciats, i d'altres, figuren esmentats per ordre alfabètic a l'apartat dedicat a la BIBLIOGRAFIA.

\section{Recorregut de l'itinerari}

El recorregut de l'itinerari discorrerà íntegrament per la comarca de l'Anoia. Així, s'iniciarà als sectors segarrencs d'aquesta comarca, per les immediacions de la Panadella, concretament a la carretera que procedeix de Carbassí, la BV - 2234. Sobre aquesta carretera es farà la primera aturada.

Posteriorment, es continuarà per l'antiga carretera nacional N - IIA, anant cap a Igualada. En passar per les proximitats del poble aturonat de Montmaneu, es faran dues noves aturades.

Posteriorment, seguint per l'esmentada N - IIA, s'arribarà a Santa Maria del Camí, anant després cap a Jorba. Abans d'arribar-hi es farà una fillola, anant cap a una antiga guixera. Posteriorment, el recorregut arribarà al darrer poble esmentat, per on es farà la darrera aturada d'aquest recorregut.

\section{Advertiments previs}

Com en altres recorreguts de RECERCA GEOLÒGICA I MINERALÒGICA... si es disposa del temps suficient, poden efectuar-se passant per totes les parades i filloles. En cas contrari, recomanem prescindir de les anomenades PARADES - CONDICIONALS.

També cal tenir en conte que part del recorregut, tant a l'inici de l'itinerari, com als seus darrers trams, es realitzarà per camins de terra, per la qual cosa caldrà prendre les degudes precaucions.

Cal tenir, com sempre, una cura molt especial de respecte a la natura, al llarg de tot el recorregut de l'itinerari, i també fora d'ell. 


\section{Descripció de l'itinerari}

Com de costum, estructurarem el recorregut de I'itinerari en una sèrie de PARADES, que anirem veient. En cadascuna d'aquestes aturades farem un breu comentari (geològic 0 mineralògic, segons s'escaigui). En cada cas indicarem, entre parèntesi, el full topogràfic on es troba l'aturada.

En aquest cas, el recorregut de l'itinerari s'inclourà dintre dels següents fulls, del "Mapa Topográfico Nacional", realitzats a I'escala 1:50.000 per I'"I.G.C. de España": 390 (dit de Cervera) i 391 (o d'Igualada). Tanmateix, si s'escau, es pot utilitzar el Mapa Topogràfic Comarcal d'Anoia, editat per l'Institut Cartogràfic de Catalunya.

Així doncs, la relació de les aturades, que composen el recorregut d'aquest itinerari és la següent

\subsection{Parada 1. EXPLOTACIONS DE CALCÀRIES DE CARBASí - LA PANADELLA, (la Panadella, terme de Montmaneu, comarca d'Anoia, subcomarca de la Segarra Anoienca). (Full 390).}

El recorregut l'iniciarem prop del poble de Carbassí; en realitat, entre aquesta localitat i la de la Panadella, a la carretera BV - 2234, que uneix els dos pobles. En aquest indret hi ha unes antigues explotacions de calcàries. Aquí farem la primera de les aturades d'aquest itinerari, a uns $2 \mathrm{Km}$ de cada un dels dos pobles.

En aquest indret afloren uns nivells carbonatats calcaris, les anomenades calcàries de Montmaneu - la Panadella. Al respecte, cal recordar que quests materials formen part de Formació Tàrrega, constitueixen aquí el Sistema lacustre de la Segarra. Aquestes calcàries, per canvi lateral de fàcies passen a la Formació Calaf, la qual es troba amplament representada més cap al NE d'un ara ens trobem. Aquests darrers materials són els que es troben al Port de la Panadella, on constitueixen una suau cinglera, una clara "cuesta. Aquesta cinglera constitueix la divisòria d'aigües entre la vall del Segre, i la de I'Anoia. Així, per sota de les calcàries, cap al Nord, neixen el riu d'Ondara i el riu Corb, tributaris del Segre. Mentre que cap al Sud ho fa el riu Anoia, tributari del Llobregat.

Per d'altra banda, en aquest lloc, on fem la present aturada, hi ha una important explotació a "cel obert" dels nivells carbonatats dels quals hem acabat de parlar. Aquestes calcàries, en bona part s'utilitzen $\mathrm{cm}$ a àrids. (fotografia 1 ). 


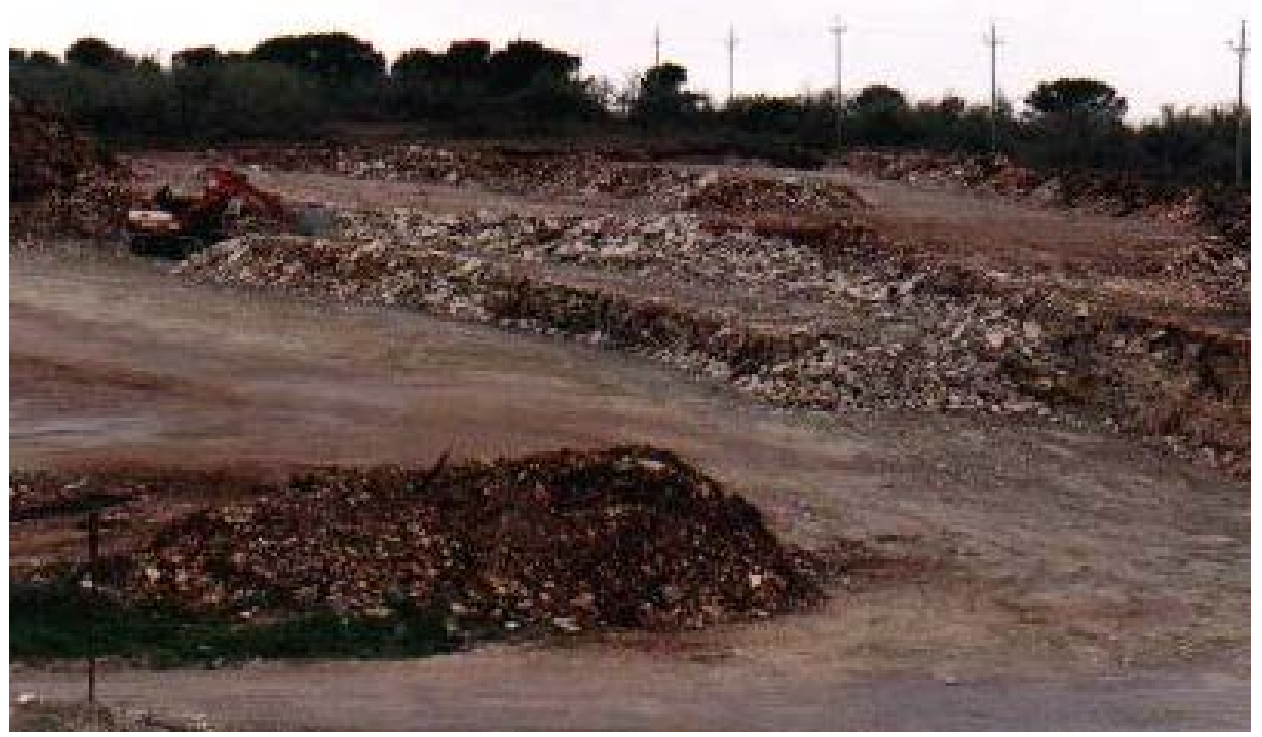

Fotografia 1. Aflorament i explotació de les calcàries de la Panadella Pedrera de Carbassí - la Panadella. Juliol del 2000

\subsection{Parada 2. EXPLOTACIÓ DE CALCÀRIES DE LA PONDEROSA, (terme municipal de Montmaneu, comarca d'Anoia, subcomarca de la Segarra Anoienca). (Full 390).}

Després d'efectuar la parada anterior, cal anar primer cap a la Panadella (utilitzant les carreteres BV - 2234 i B - 221. Després caldrà continuar per la carretera nacional N - IIA. En arribar al Barranc de Montmaneu, caldrà fer una nova aturada, just al costat de l'Autovia A - 2. Així, des de la parada anterior, haurem recorregut uns 4’5 Km, aproximadament.

En aquest recorregut, primer haurem trobat els nivells carbonatats de les calcàries de la Panadella. Per sota, haurem vist uns nivells de calcolutites i sorres. I ara hem trobat uns nivells carbonatats, les anomenades calcàries d'Albarrells. Tots aquests materials formen part de la Formació Tàrrega i del Complex Al.luvial de la Segarra.

En aquest indret, hi ha una explotació de les esmentades Calcàries d'Albarrells. (fotografia 2). 


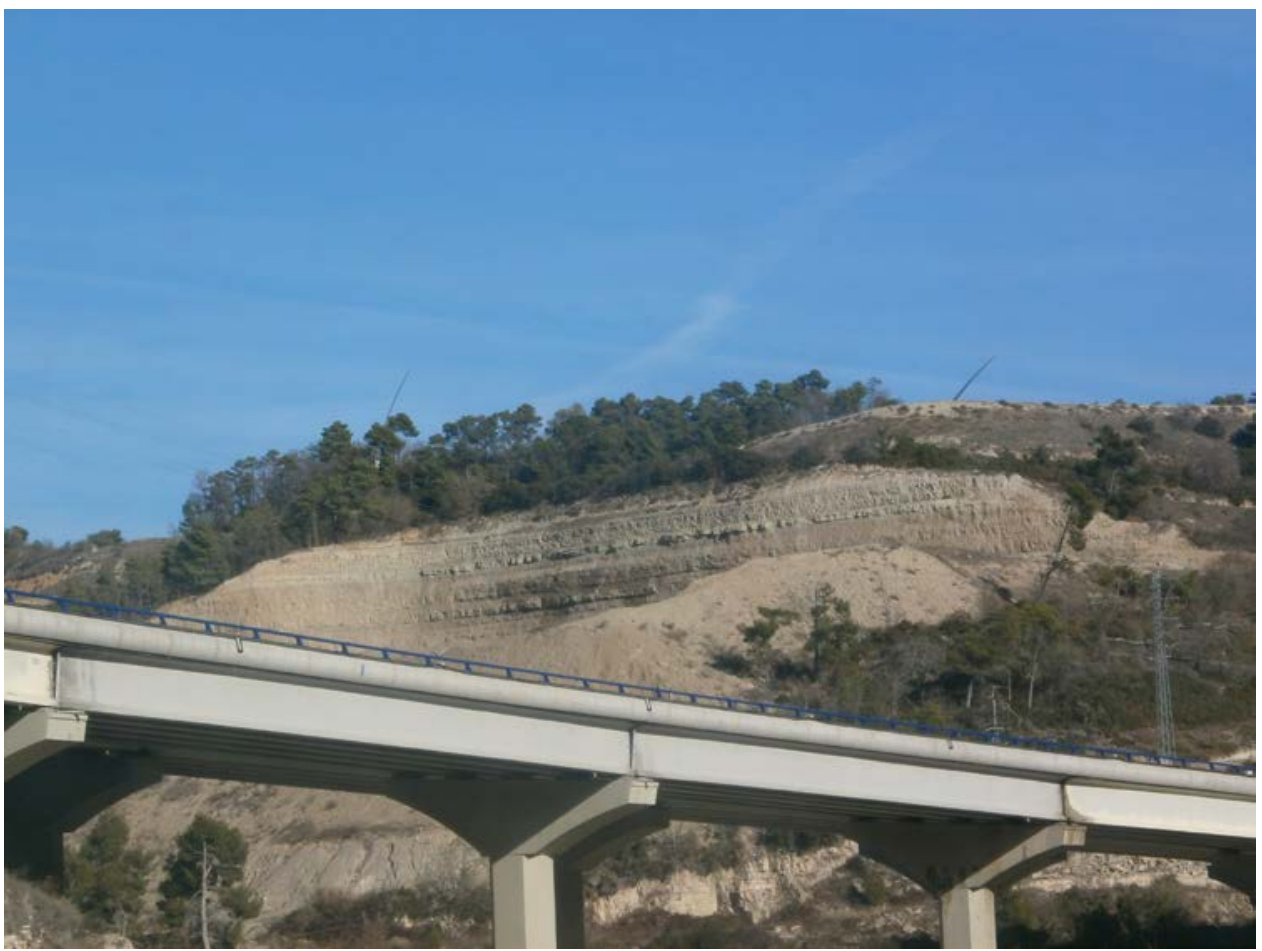

Fotografia 2. Explotació dels materials carbonatats de les calcàries d'Albarrells (Formació Tàrrega).

Pedrera "La Ponderosa". Montmaneu

\subsection{Parada 3. ESLLAVISSADA DE MONTMANEU, AUTOVIA A - 2, (terme de Montmaneu, comarca d'Anoia, subcomarca de la Segarra Anoienca). (Full 390).}

Des de la parada anterior, cal continuar per la carretera N-IIA, seguint cap a Santa Maria del Camí i cap a Jorba. En arribar a les immediacions del Km 535'5, caldrà agafar un trencall que passa a l'altra banda de I'Autovia $A-2$, per tal de fer una nova aturada. Aquesta aturada la farem a uns $2 \mathrm{Km}$ de la parada anterior.

En aquest recorregut, haurem continuat trobant els materials esmentats a l'aturada anterior. Per sota trobarem uns nivells de calcolutites i calcàries. Aquests són els materials que afloren a I'indret de l'aturada. Aquests materials, a l'igual que els anteriors pertanyen a la Formació Tàrrega i formen part del Complex Al·luvial de la Segarra.

En aquest indret, on afloren les calcolutites i les sorres, es van produir unes esllavissades sobre les obres que s'estaven fent per la construcció de l'Autovia $A-2$. Per tal de solucionarho es van de fer una sèrie d'actuacions que van malmetre enormement el medi natural que envolta l'esmentada via. (fotografia 3). 


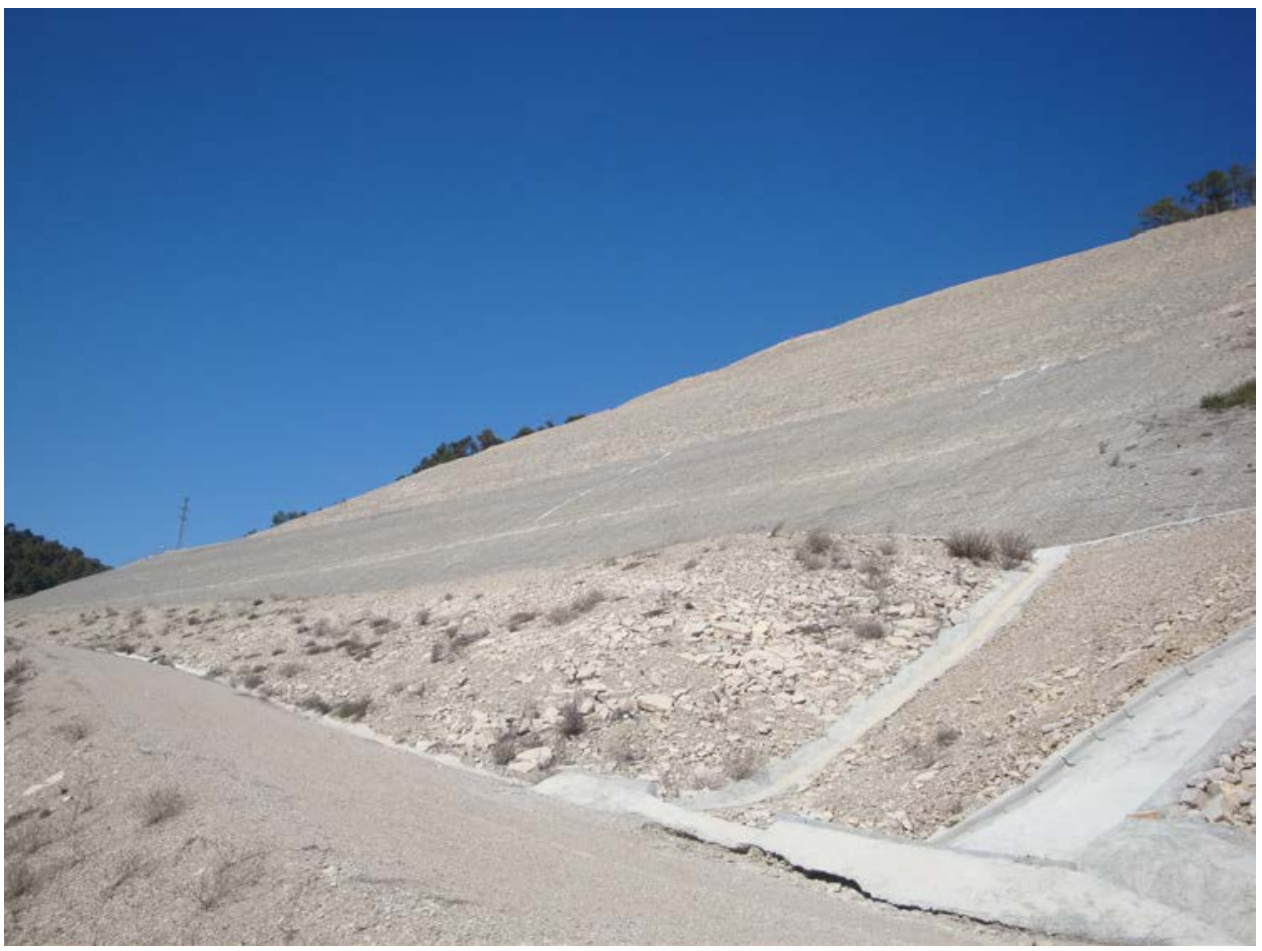

Fotografia 3. Obres de restauració de l'esllavissada sobre l'Autopista A - 2

\subsection{Parada 4. GUIXERA DE JORBA, (terme municipal de Jorba, comarca de I'Anoia). (Full 391)}

Després de fer la parada anterior, cal fer un recorregut per la carretera nacional $\mathrm{N}$-IIA tot anant sempre cap a ponent. Així, aviat s'arribarà al trencall d'Argençola )per la dreta), després a les immediacions de la població de Porqueres i poc després al poble de Santa Maria del Camí, que caldrà sobrepassar. Poc després es trobarà per la dreta el trencall per la dreta, que s'encamina cap a Clariana i cap a I'antiga explotació de guixos. Caldrà agafar aquest camí asfaltat. En arribar a l'antiga guixera es pot fer una nova aturada. Així, des de la parada anterior, haurem recorregut uns $8 \mathrm{Km}$, aproximadament.

En aquest recorregut, per sota dels materials anteriors, haurem trobat uns nivells grisencs, calcolutítics. Aquests són els que corresponen lateralment als nivells dels guixos de Clariana, que veurem després. Més endavant, hem trobat els nivells rogencs de les calcolutites de la Formació Artés.

Posteriorment, en pujar cap a l'antiga explotació de guixos, haurem tornat a trobar els nivells grisencs i veurem ara els nivells dels Guixos de Clariana. Aquests és situen dintre dels materials de la Formació Artés i del Complex Al.luvial de l'Anoia.

En aquest indret, aquests guixos han estat explotats per l'empresa Vilobí Gyps (que posteriorment va esser adquirida per una empresa britànica, la Brittis Gypsum). Tot això fa uns anys. A l'actualitat es troba aturada l'explotació i s'ha situat en ella un abocador. (fotografía 4). Tot i així, per entrar a l'antiga guixera cal demanar l'oportuna autorització. En cas d'entrar-hi, es poden veure clarament els nivells de guixos explotats. Entre els, es 
fan clarament palès el GUIX LAMINAR, molt ostentós. Es tracta sempre de guixos secundaris. També es poden veure exemplars de GUIX FIBRÓS; però amb tot, la varietat més abundant és la del GUIX MASSIU.

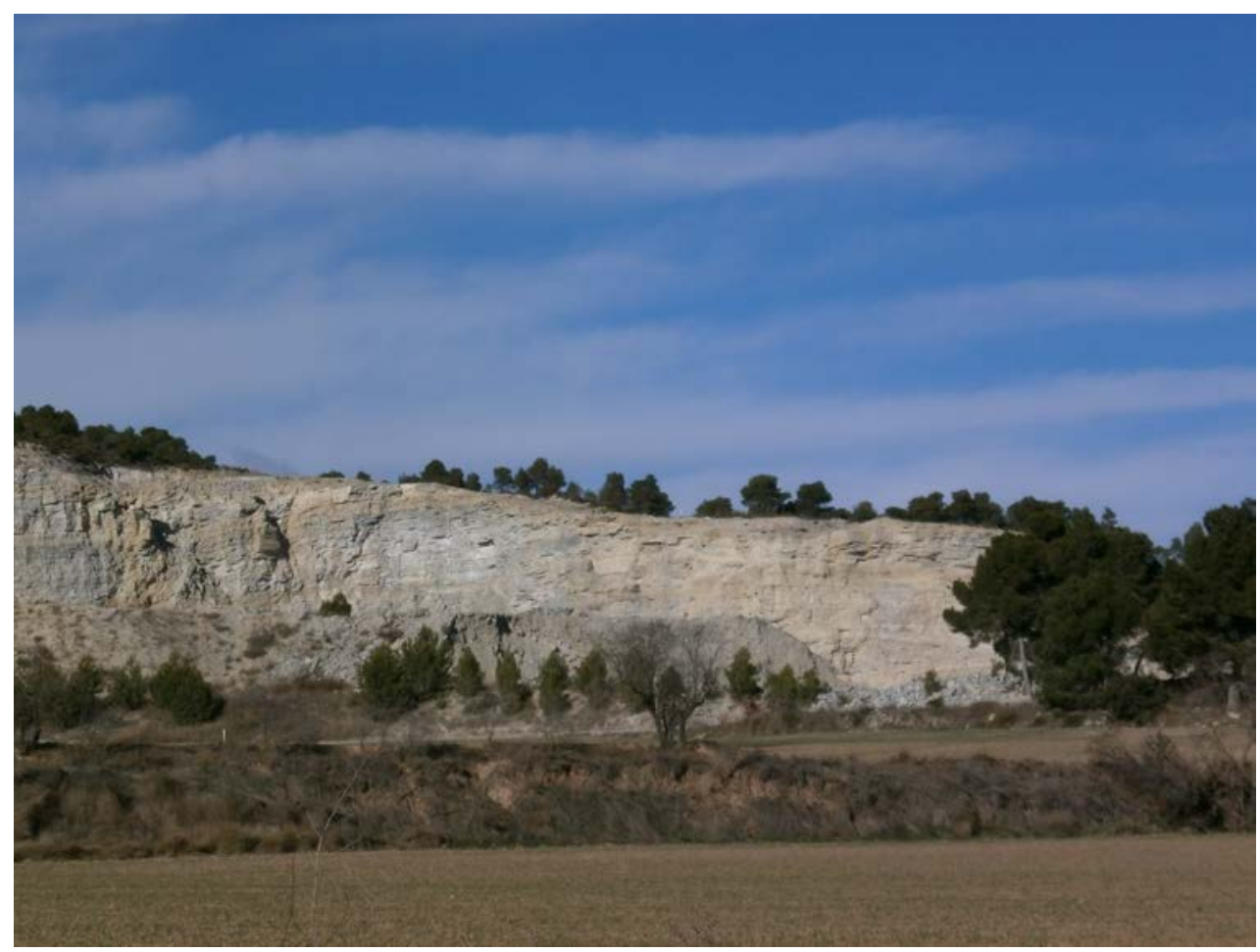

Fotografia 4. Un aspecte de l'antiga explotació de guixos de Jorba. Aflorament dels guixos de Clariana

\subsection{Parada 5. SORTIDA DE JORBA CAP A SANT GENÍS, (terme municipal de Jorba, comarca de l’Anoia). (Full 391)}

Després de fer la parada anterior, tornar cap a l'antiga carretera nacional $\mathrm{N}-\mathrm{IIA}$, amb la intenció d'arribar fins al poble de Jorba. Abans d'arribar-hi, deixarem per l'esquerra el trencall de Copons i de Calaf. Després, en arribar a Jorba, cal quasi sobrepassar-la, per tal de fer una nova aturada a la sortida de la població. Així, des de la parada anterior, haurem recorregut uns 3’5 Km més, aproximadament.

En aquest recorregut, hem tornat a trobar afloraments dels nivells rogencs de la Formació Artés. Així, haurem vist per arreu gresos i calcolutites continentals, de tonalitats vermelles, com a conseqüència del poc HEMATITES present entre els minerals que composen les roques anteriors. Aquests materials els trobem per arreu en torn a la població de Jorba. (fotografia 5). 


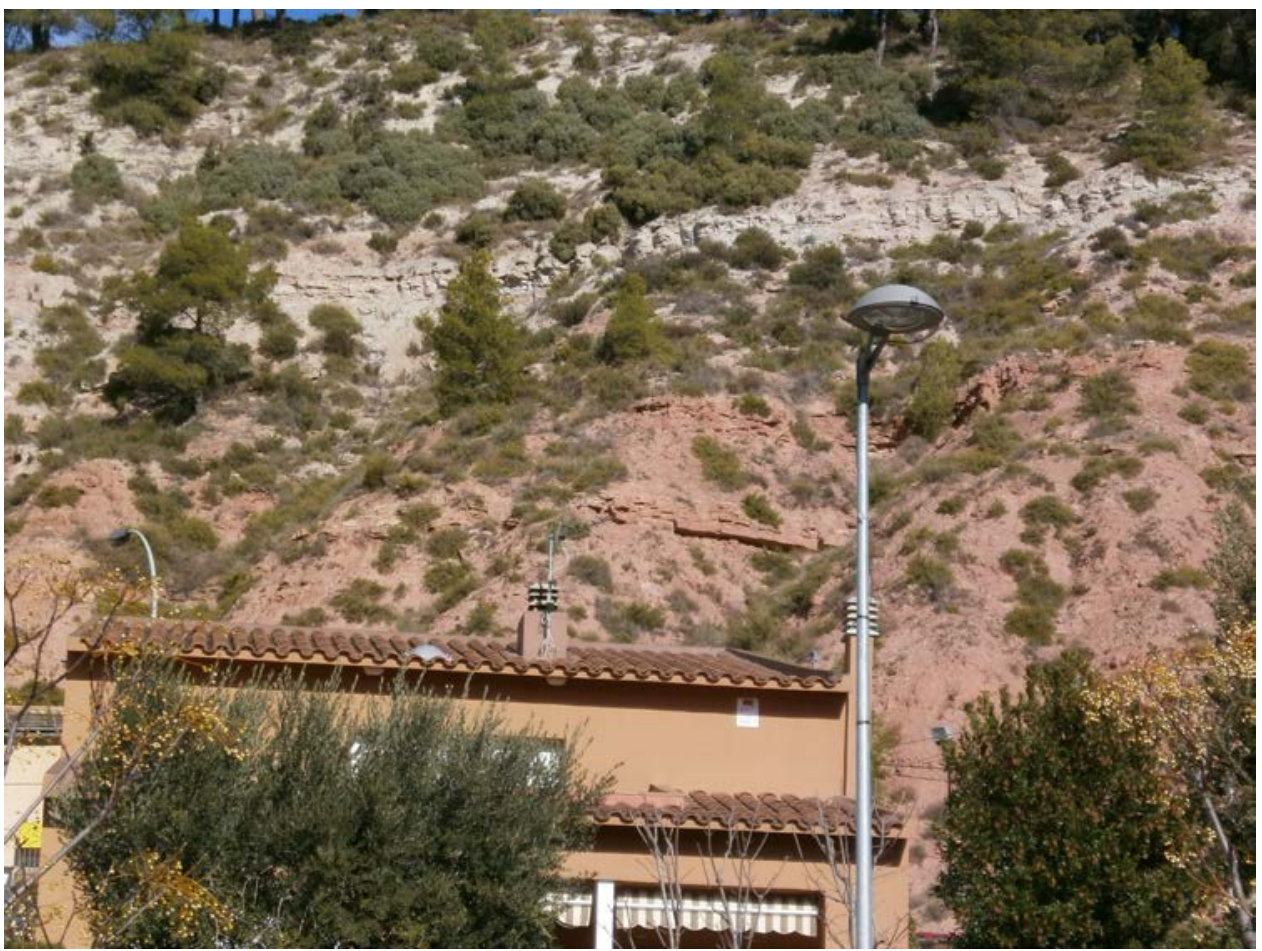

Fotografia 5. Afloraments dels materials de la Formació Artés a Jorba

Sota hi ha els trams rogencs de gresos i calcolutites. I a sobre ja comencen a pareixen els trams blanquinosos de les calcolutites i guixos (guixos de Clariana), d'aquesta mateixa formació

En aquest indret finalitza el recorregut de l'itinerari. 


\section{Bibliografia}

GUIMERÀ, J. et altri (1992).- Geologia (II), Història Natural dels Països Catalans, Vol.2, 547 pag. Enciclopèdia Catalana, S.A. Barcelona.

MATA-PERELLÓ, J.M. (1990).- Inventari Mineralògic de la comarca d'Anoia. Revista Xaragall, $\mathrm{n}^{\circ} 24,40$ pag. Manresa.

MATA-PERELLÓ, J.M. (1991).- Els Minerals de Catalunya. Arxius de la Secció de Ciències, t. XCIII, 442 pag. Institut d'Estudis Catalans. Barcelona.

MATA-PERELLÓ, J.M. (1996).- Recerca geològica i mineralògica per les comarques d'Anoia, Segarra, Conca de Barberà, Segarra i Urgell: des de Jorba a Preixens. Inèdit, 19 pàgines, Manresa.

MATA-PERELLÓ, J.M. (1997).- Recerca geològica i mineralògica per les guixeres de la comarca d'Anoia: des d'Òdena i l'Espelt a Jorba i a Clariana. Inèdit, 11 pag. Manresa.

MATA-PERELLÓ, J.M. (1999).- Recerca geològica i mineralògica per la comarca d'Anoia: des d'Òdena i l'Espelt a Jorba, i des de Clariana i Argençola a Bellmunt i Aguiló. Inèdit, 10 pag. Manresa.

MATA-PERELLÓ, J.M. (2000).- Recerca geològica i de reconeixement dels georrecursos per les pedreres de la comarca d'Anoia: des d'Òdena i l'Espelt a Sant Martí de Tous, i des de Clarianai i Argençola a Carbassí. Algeps, sèrie B, $n^{\circ}$ 172, 11 pag. Manresa.

MATA-PERELLÓ, J. M. (2001).- Recerca geològica i geoambiental per les comarques d'Anoia i de la Segarra: des d'Òdena i l'Espelt cap a Sant Genís i Jorba, i des de Montmaneu a Sant Pere dels Arquells. Inèdit, 8 pàgines. Manresa.

MATA-PERELLÓ, J. M. (2012).- Recorregut de recerca geològica i geoambiental per les comarques del Bages, d'Anoia i de la Segarra: des de Maians i Òdena cap a Jorba, la Panadella i a Sant Pere dels Arquells. Inèdit. 14 pàgines. Manresa.

RIBA, O. et altri (1976).- Geografia Física dels Països Catalans, Edit. Ketres, 254 pàgines. Barcelona. 